\title{
US conflict-of-interest case draws attention across continent
}

A conflict-of-interest case in Oregon is gaining attention across the United States and Canada for the precedent it may set regarding how much physicians should disclose to patients about their financial ties to medical companies.

Two physicians in Salem, Dr. Matthew Fedor and Dr. Kyong Turk, were charged under Oregon's Unlawful Trade Practices Act. The doctors implanted defibrillators and pacemakers without telling patients that they had been paid by the devices' manufacturer, Biotronik, to train sales representatives from the company.

In August, both physicians agreed to pay US\$25000 to settle the case. Though admitting no wrongdoing, Fedor also agreed to inform future patients of financial ties to drug or device makers. Turk is now retired.

Fedor and Turk were part of a Biotronik program to train and certify sales representatives to assist doctors in implanting the company's devices. They were paid $\$ 400-\$ 1250$ per surgery when a trainee was present.

This practice, however, is not only common but also important, says Brian Parrott, one of Fedor's lawyers. "It's essential to have someone from the

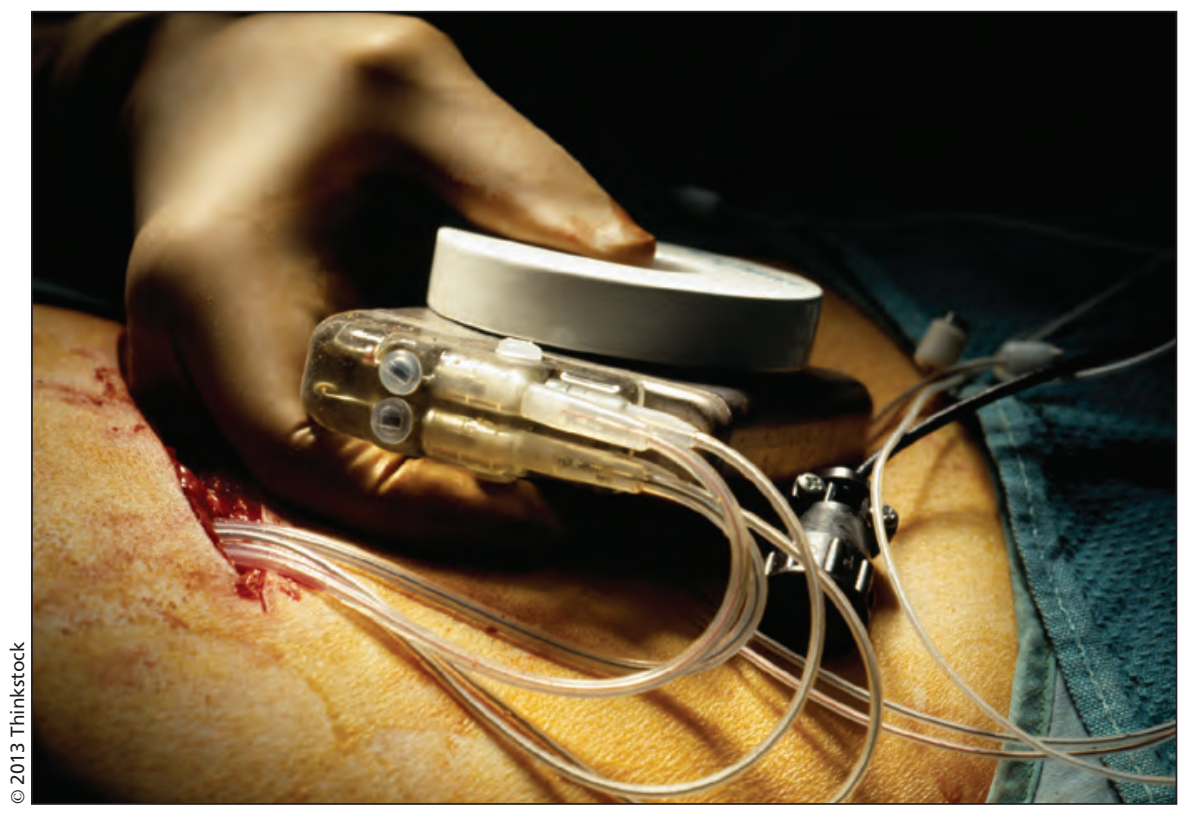

Two US physicians were charged under Oregon's Unlawful Trade Practices Act for implanting defibrillators and pacemakers without disclosing to patients that they had been paid by the devices' manufacturer.

state had used consumer protection laws in this way before, he adds. He expects the state will use the precedent of their settlement to take action against other doctors.

The state will indeed go after other physicians who fail to disclose conflicts of interest, confirms Hart, though he hopes prosecutions won't be neces-

\section{"Oregon law requires tradespeople, including physicians, to disclose any conflict of interest."}

company there," he says "They own the equipment to calibrate the device," and are the only people who know how to do so.

According to Oregon's Department of Justice, however, the physicians stood to gain financially every time they used a Biotronik device, which was a conflict of interest.

"Oregon law requires tradespeople, including physicians, to disclose any conflict of interest," says David Hart, the assistant attorney general who brought the prosecution.

Yet Parrott says he and his client do not believe the state's Unlawful Trade Practices Act applies to physicians. No sary. "The goal is not to take people to court every time," he says. "I hope doctors will be transparent and tell their patients what they have a right to know."

The case has drawn the attention of physicians across the US, as they wait to see if other states follow Oregon's lead. It is unclear whether a similar case could be brought in Canada. It's unknown whether similar conflicts of interest are common in Canada due to lack of information, says Kathryn Clarke, a spokeswoman for the College of Physicians and Surgeons of Ontario. "I have been unable to identify any case heard by our discipline committee that is analogous to the facts presented in the US case," she says.

Of course, rules governing medical conflicts of interest exist in Canada, though they vary between provinces and territories. In Ontario, the law states that physicians or their family members receiving benefits from a medical supplier constitues a conflict of interest, and the practice is banned. The benefit can take the form of direct payments, rewards or indirect benefits such as forgiveness of debts. The Canadian Medical Association's Code of Ethics also calls on doctors to "resist any influence or interference that could undermine your professional integrity."

The medical profession in Canada is self-regulating. The provincial colleges of physicians police their members and enforce applicable laws in response to patient complaints. The college in Ontario receives some complaints alleging conflict of interests each year, says Clarke, but these typically account for less than $1 \%$ of all the matters it investigates. Possible sanctions include reprimands, fines of up to $\$ 35000$ and the suspension or revocation of licences to practise in the province. - Brian Owens, St. Stephen, NB

CMAJ 2013. DOI:10.1503/cmaj.109-4602 